\title{
Sosialisasi Kiat Berwirausaha Untuk Meningkatkan Penghasilan Keluarga Di Desa Sumber Jaya Kabupaten Bekasi
}

\author{
Matdio Siahaan ${ }^{1,{ }^{*}}$, Endah Prawesti Ningrum ${ }^{1}$ \\ ${ }^{1}$ Fakultas Ekonomi; Universitas Bhayangkara Jakarta Raya; Jl. Raya Perjuangan Marga Mulya \\ Bekasi Utara, 02188955882; e-mail: matdio.siahaan@dsn.ubharajaya.ac.id, \\ endah.prawesti@dsn.ubharajaya.ac.id \\ * Korespondensi: e-mail: matdio.siahaan@dsn.ubharajaya.ac.id
}

Submitted: 15/12/2021; Revised: 18/12/2021; Accepted: 28/12/2021; Published: 31/12/2021

\begin{abstract}
Community service activities aims to build community awareness in Sumber Jaya Village, South Tambun District, Bekasi Regency West Java to have business, creative, and innovation in managing business, in order to realize a better the next future and able to be financially independent. Through an understanding of entrepreneurship tips it is beneficial to increase family income. Socialization and Outreach of community to be able to entrepreneurship in the field of creative economics, especially for the mother PKK as the main driving motor of the family economy. The results found from this entrepreneurship counseling provide the benefits of science and learning for those who conduct business. They will become skilled and able to develop enterprises, both by management resources and financial management with the principles of accountability and profitability.
\end{abstract}

Keywords: Accounting, Enterpreneurship, Income

\begin{abstract}
Abstrak
Kegiatan Pengabdian Kepada Masyarakat ini bertujuan untuk membangun kesadaran masyarakat di Desa Sumber Jaya, Kecamatan Tambun Selatan, Kabupaten Bekasi Jawa Barat untuk memiliki usaha, kreatif, dan inovasi dalam mengelola usaha, guna mewujudkan cita-cita di masa depan yang lebih baik dan mampu mandiri secara keuangan. Melalui pemahaman kiat berwirausaha manfaatnya untuk meningkatkan penghasilan keluarga. Sosialisasi dan Penyuluhan masyarakat agar mampu berwirausaha di bidang ekonomi kreatif, terutama bagi ibu PKK sebagai motor penggerak utama ekonomi keluarga. Hasil yang didapati dari Penyuluhan Kewirausahaan ini memberikan manfaat IImu Pengetahuan dan Pembelajaran bagi mereka yang melaksanakan usaha. Mereka akan menjadi terampil dan mampu mengembangkan usaha, baik secara manajemen sumber daya dan manajemen keuangan dengan prinsip-prinsip akuntabilitas dan profitabilitas.
\end{abstract}

Kata kunci: Akuntansi, Kewirausahaan, Penghasilan

\section{Pendahuluan}

Kegiatan Pengabdian Kepada Masyarakat yang dilaksanakan di Desa Sumber Jaya Tambun adalah salah satu Desa yang ada di Kecamatan Tambun Selatan Kabupaten Bekasi. Jawa Barat dengan luas wilayah lebih kurang sekitar $4.310 \mathrm{Ha},(3,38 \%)$. Dengan curah hujan rata-rata $1.500 \mathrm{~mm} /$ tahun, suhu 27 - $35 \mathrm{C}$ per hari, curah hujan/kelebapan $65 \%$ per hari, jumlah penduduk Desa Tambun Selatan dengan bulan Maret 2017 lebih kurang 387.640 jiwa. 

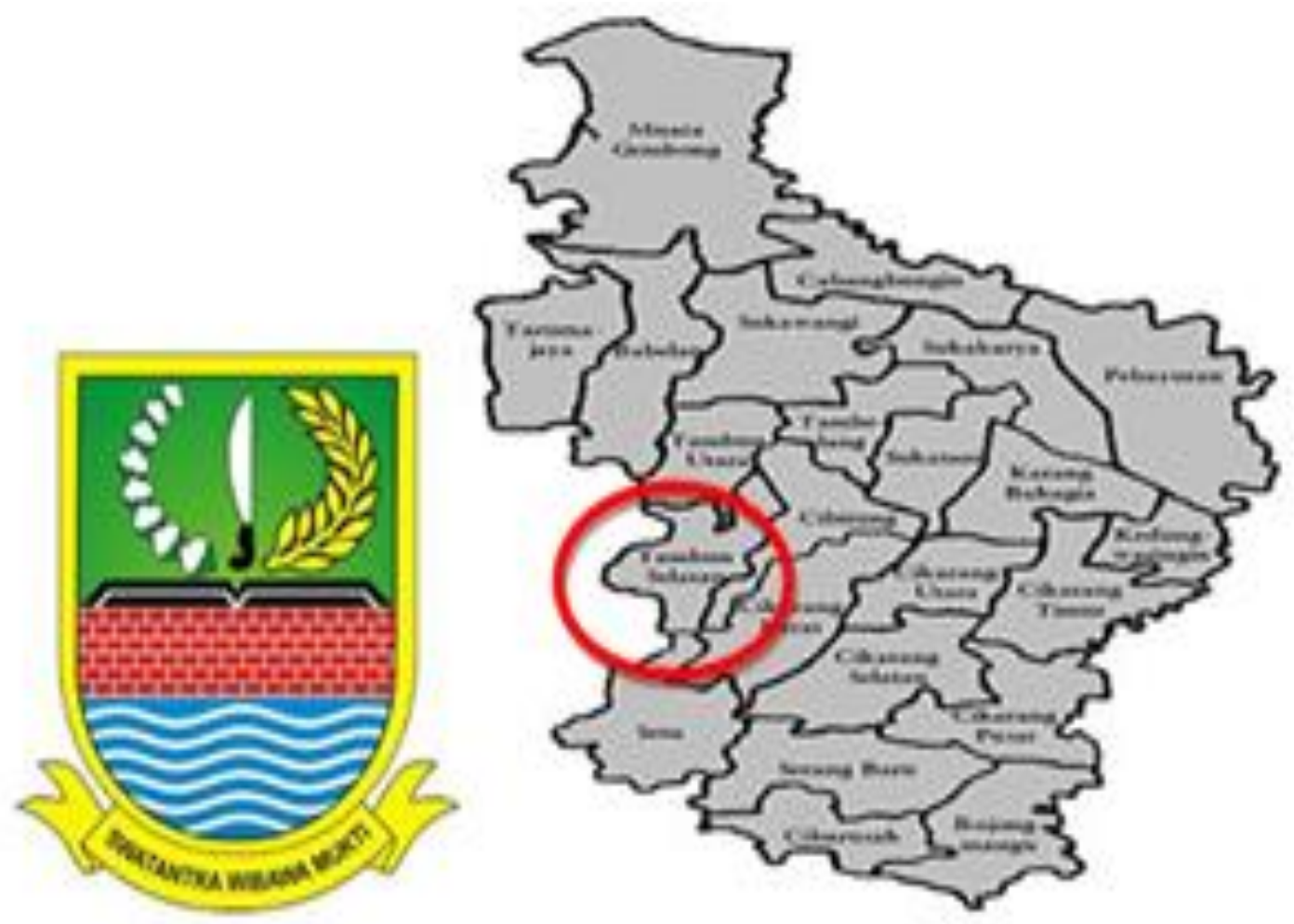

Sumber: (Kementerian Perdagangan, 2013).

Gambar 1. Peta Wilayah Kecamatan Tambun Selatan

Gambar 1 menunjukkan peta wilayah kecamatan Tambun Selatan. Gambar 2 menunjukkan lokasi Desa Sumberjaya Kecamatan Tambun Selatan.

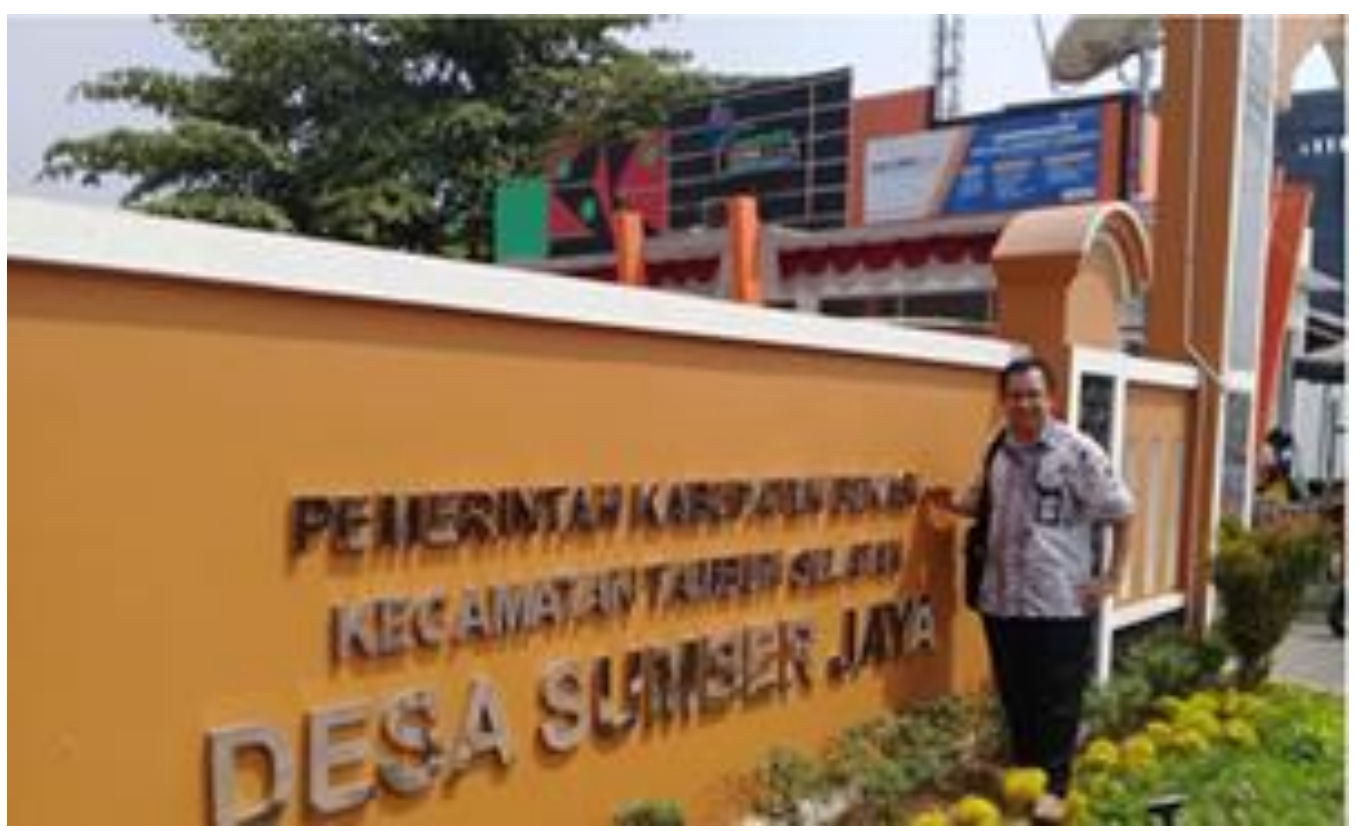

Sumber: Hasil Pelaksanaan (2021)

Gambar 2. Desa Sumber Jaya, Pada saat survey

Berikut ini adalah daftar kecamatan dan kelurahan di Kabupaten Bekasi, Provinsi Jawa Barat, Indonesia. Kabupaten Bekasi memiliki 23 kecamatan, 7 kelurahan, 180 desa, dan 11 
pulau. Pada tahun 2017, jumlah penduduk mencapai 2.554.376 jiwa dengan luas wilayah $1.224,88 \mathrm{~km}^{2}$ dan sebaran penduduk $2.085 \mathrm{jiwa} / \mathrm{km}^{2}$.[1] lbu kota berada di Cikarang Pusat (sebelumnya bernama: "Karangjati" (antara tahun 1969-1984) atau "Djonggor" (antara tahun 1950an awal-1969) atau "Tambi Sembilan" (sebelum dekade 1950an), berdiri pada tahun 1894, kemudian terjadi pemekaran desa dan berganti nama sekitar dekade 1980-an pertengahan, tepatnya tahun 1984), serta memiliki kode pos 17211 sampai 17770 dan kode area telepon +62 21 (untuk wilayah daratan) dan +62-236 (untuk wilayah kepulauan di Kabupaten Bekasi (meliputi pulau Bawang, pulau Arang dan pulau Kelapa serta 8 pulau lain).Kabupaten Bekasi berdiri pada tanggal 15 Agustus 1950 menurut dasar hukum Undang-Undang Republik Indonesia nomor 14 tahun 1950 serta berada di dataran rendah dan pada ketinggian $\pm 2-40$ meter di atas permukaan laut (dpl) dengan saat itu terbagi atas 15 kecamatan dan 118 desa, yang saat itu beribu kota di Kota Bekasi. Memiliki luas wilayah $1.224,88 \mathrm{~km}^{2}$ yang meliputi daratan $860 \mathrm{~km}^{2}$ dan kepulauan (meliputi pulau Bawang, pulau Arang dan pulau Kelapa serta 8 pulau-pulau lain) $559 \mathrm{~km}^{2}$ serta berpenduduk 2.575.000 jiwa pada bulan April 2014 dan kepadatan penduduk 1.820 jiwa per $\mathrm{km}^{2}$, menjadikan kabupaten terpadat di Jawa Barat, setelah kabupaten Bandung dan kabupaten Bogor. Daftar kelurahan dan Desa di Kecamatan Tambun Selatan, adalah sebagai berikut: Desa Jatimulya, Lambangjaya, Lambangsari, Mangunjaya, Mekarsari, Setiadarma, Setiamekar, Sumberjaya, Tambun, Kelurahan Tridaya Sakti.

Batas-batas Desa Sumber Jaya yaitu Sebelah Utara Desa Jejalen, sebelah Timur Desa Setia Mekar, sebelah selatan Desa Mekarsari, dan sebelah Barat Kali Bekasi/ Kec. Tambelang. Penduduk Desa Sumber Jaya memiliki bidang usaha yang bervariasi yaitu pegawai negeri, pegawai swasta, pedagang, buruh tani. Kegiatan lbu PKK diantaranya wirausaha/kelompok usaha kerajinan, usaha kuliner, dan usaha di rumah/warung (Sinungan, 2000). Bergerak di bidang jasa / tukang bangunan, supir, tukang ojek/gojek.Sedangkan para Pemuda - pemudi dan Karang Taruna sudah ada yang bekerja, dan sebagian besar belum mempunyai pekerjaan (pengangguran).

Dengan adanya kondisi sumber daya manusia yang belum memiliki keahlian, dan ketrampilan yang kurang atau rendah (serba keterbatasan), maka sangat diperlukan peningkatan kemampuan di berbagai bidang ketrampilan melalui Sosialisasi Kiat Berwirausaha untuk Meningkatkan Penghasilan Keluarga Di Desa Sumber Jaya, Kecamatan Tambun Selatan, Kabupaten Bekasi, Jawa Barat (Moelyono, 2010). Pembinaan kewirausahaan dari para ahli/kepakaran di berbagai bidang yang disesuaikan dengan tingkat kebutuhan yang ada di masyarakat Desa Sumber Jaya (Handoko, 1994), terutama untuk mewujudkan program pemerintah yakni "Pengentasan Kemiskinan" melalui program Pengabdian Kepada Masyarakat diharapkan bisa berkurang melalui kegiatan lbu PKK dan Kader lbu PKK tingkat RW. Berdasarkan pengamatan kami minat untuk berwirausaha persentasinya masih cukup rendah, oleh karena itu agar terus didorong melalui UKM yang meliputi Usaha Kelompok Kerajinan Kuliner, dan bagi Usaha di Rumah agar bisa menjadi home industry di Desa Sumber Jaya, Kecamatan Tambun Selatan Kabupaten Bekasi Jawa Barat (Sari, 2018). Dengan adanya 
pemberian sosialisasi masyarakat tentang "Kewirausahaan di Bidang Ekonomi Kreatif, di Masarakat Desa Sumber Jaya tersebut, ini merupakan penerapan pendidikan kewirausahaan yang berdampak langsung terhadap peningkatan penghasilan masyarakat bawah di Desa Sumber Jaya, Kecamatan Tambun Selatan, Kabupaten Bekasi, dengan adanya Sosialisasi Kewirausahaan di Bidang Ekonomi Kreatif, menambah pengetahuan dan ketrampilan meliputi Kiat Berwirausaha, Strategi Pemasaran, Proses Produksi, Kepemimpinan, dan pemahaman tentang Akuntansi atau membuat laporan keuangan (Hejirachman \& Husna, 2003) (Suryana, 2013). Yang nantinya di harapkan hasil yang dicapai dapat meningkatkan Kesejahteraan dan Penghasilan keluarga. Yang ada di lingkungan masyarakat desa. Di sisi lain juga mendukung sepenuhnya yang berhubungan dengan BUMDES antara lain, menurut pendapat (Bramantyo, 2017), menyatakan bahwa pada prinsipnya hadirnya BUMDES harus mampu menjadi wadah yang merangkul dan mengembangkan potensi dan usaha masyarakat desa, harus menjadi motivasi dan mendorong kepada para UKM yang ada di Desa / Kelurahan, khususnya masyarakat Desa Sumber Jaya, Kecamatan Tambun Selatan, Kabupaten Bekasi, Jawa Barat.

\section{Metode Pelaksanaan}

Kegiatan Pengabdian masyarakat ini dilakukan di Gedung / Kantor Desa Sumber Jaya, Jln. Raya Tambun-Tambelang, Kp. Warung Asem, RT.001/ RW.001, Kode Pos 17519. Kecamatan Tambun Selatan, Kabupaten Bekasi Jawa Barat, Metode pengabdian masyarakat yang telah dilakukan ini menggunakan metode Sosialisasi dan Simulasi, Role Play yang di praktekkan oleh peserta dan nasa sumber serta Tanya jawab. Metode penyuluhan digunakan menyampaikan pengetahuan secara umum. Dan selanjutnya persiapan observasi dan pembuatan proposal (Fandyansari, 2019). dengan jadwal pelaksanaan kegiatan adalah sebagai berikut :

\subsection{Tahap Pelaksanaan}

Pengabdian Pada Masyarakat Yang Dilaksanakan Oleh Tim Dosen Fakultas Ekonomi Universitas Bhayangkara Jakarta Raya, Dimulai Pada Hari Selasa, 15 Oktober 2019. Dari Jam. 08.00 - 15.00 Wib, Di Hadiri Oleh 20 Orang Peserta. Kegiatan Ini Dimulai Dengan Pembacaan Doa Dari Perangkat Desa Sumber Jaya, Dan Dilanjutkan Dengan Kata Sambutan Pertama Oleh Bapak H. Matam, Spdi, Selaku Kepala Desa Sumber Jaya, Kecamatan Tambun Selatan, Kabupaten Bekasi, Dan Dilanjutkan Kata Sambutan Oleh Bapak Matdio Siahaan, Se.Mm, Selaku Perwakilan Dari Tim Dosen Fakultas Ekonomi Universitas Bhayangkara Jakarta Raya, Dan Juga Selaku Ketua Pelaksana Kegiatan Pengabdian Masyarakat. Dan Dilanjutkan, Sosialisasi Kiat Berwirausaha, Oleh Bapak Indra Lubis,Sh.Mm,Dan Ridwan Anwar, Se,Mm Di Ruang Serba Guna Kantor Desa Sumber Jaya Tambun Selatan. Peserta Ibu Pkk Tingkat Rw Dan Kader, Kelompok Usaha Kecil / Usaha Dirumah, Dan Para Tamu Pengurus RT Dan RW. Dalam upaya peningkatan pendapatan rumah tangga untuk kesejahteraan keluarga menggunakan metode pendekatan yang digunakan adalah a) Memberikan ilmu pengetahuan, 
keterampilan, bagaimana cara meningkatkan pendapatan rumah tangga dengan membuat site sambas agar dapat mandiri dan sejahtera; b) Memberikan cara pengelolaan ekonomi rumah tangga dengan membuat wirausaha sukses untuk mengelolah hasil kebun petai tersebut; c) Memberikan motivasi agar memperoleh pendapatan yang maksimal dan pengeluaran minimal artinya pengeluaran disesuaikan dengan kebutuhan primer (pokok) dan menekan kebutuhan sekunder (pelengkap) agar membiasakan pola hidup hemat; d) diakhiri dengan doa penutup. oleh biro umum pemerintahan desa sumber jaya.

\section{Hasil dan Pembahasan}

Pengabdian masyarakat ini bertujuan untuk memberikan ilmu pengetahuan dan ketrampilan serta menumbuhkan minat kewirausahaan bagi masyarakat Desa Sumber Jaya, Kecamatan Tambun Selatan, Kabupaten Bekasi, dimana Kegiatan pengabdian masyarakat dilakukan sehari, tanggal 15 Oktober 2019, dengan 3 Orang Nara Sumber, terdiri 1 (satu) Orang Ketua, dan 2 (dua) Orang Anggota, dan total peserta sebanyak 20 orang terdiri dari unsur Ibu PKK, UKM dan Para Usaha Kuliner, Masyarakat Desa Sumber Jaya, Tambun Selatan, Kabupaten Bekasi (Aditya, 2015).

\subsection{Kondisi sebelum dilakukan Pengabdian Kepada Masyarakat}

Masyarakat Desa Sumber Jaya, Kecamatan Tambun Selatan, Kabupaten Bekasi, di latar belakangi dengan penghuninya adalah sekitar $40 \%$ masih penduduk lokal, serba keterbatasan, belum pernah mendapatkan penyuluhan dan pelatihan mengenai Kiat Berwirausaha, bagaimana cara memasarkan usahanya secara strategi pemasaran yang baik dan kompetitif, belum pernah mendapatkan pemahaman bagaimana memproses produksi usahanya dengan baik dan Inovasi, dan belum mengetahui secara teori mengenai Kepemimpinan, serta bagaimana cara membuat laporan keuangan yang sederhana untuk UKM (Narpati, 2018). Untuk itu secara rinci dapat dijelaskan mengenai kondisi sebelum dilakukannya Pengabdian Kepada Masyarakat adalah, sebagai berikut a) Masalah kualitas SDM (Keahlian, keterampilan, dan pendidikan; b) Masalah pola pikir individual dalam rumah tangga artinya belum adanya kerjasama antara suami, istri, dan anak dalam pemakaian keuangan keluarga. Khususnya dalam pengelolaan keuangan pendapatan rumah tangga didalam keluarga; c) Masalah belum paham dan mengerti dalam hal kiat berwirausaha yang baik, dan kepemimpinan, belum paham dan mengerti bagaimana cara meningkatkan pendapatan rumah tangga agar mandiri dan sejahtera; $d$ ) Masalah belum paham dan mengerti bagaimana cara teknik dan strategi pemasaran dan manajemen produksi yang baik dan kompetitif; e) Masalah belum pernah mendapatkan pengetahuan dan keterampilan mengenai cara membuat catatan akuntansi dan membuat laporan keuangan yang sederhana, khususnya untuk usaha UKM.

\subsection{Kondisi sesudah dilakukan Pengabdian Kepada Masyarakat}

Manfaat yang didapatkan dari penyuluhan Masyarakat Kewirausahaan di bidang ekonomi kreatif pada dasarnya sangat bermanfaat bagi masyarakat Desa Sumber Jaya, 
Kecamatan Tambun Selatan. Kabupaten Bekasi, dengan penyuluhan diseminasi/pelatihan sangat besar bagi pengelola Usaha UKM, dan bagi usaha Kuliner yang di kelola oleh Ibu PKK dan Masyarakat.

Hasil yang di dapat dari kegiatan Pengabdian Kepada Masyarakat Desa Sumber Jaya Kecamatan Selatan, Kabupaten Bekasi, yaitu secara keseluruhan peserta yang hadir dari unsur Ibu PKK, UKM dan para usaha kelompok tani menambah ilmu pengetahuan dan wawasan dan ketrampilan, meliputi a) Memahami Pengetahuan tentang Kiat Kewirausahaan untuk UKM dan Kelompok Usaha Tani, Para Usaha di Rumah, sejenis Kuliner; b) Memahami bagaimana cara memasarkan dagangannya, melalui Strategis Pemasaran yang Unggul dan Sukses; c) Memahami bagaimana membuat Catatan Akuntansi dan Laporan Keuangan yang Baik untuk UKM.

Berikut merupakan dokumentasi foto bersama dengan Kepala Desa dan Aparat Desa pada kegiatan Pengabdian Kepada Masyarakat Desa Sumber Jaya, Kecamatan Tambun Selatan, Kabupaten Bekasi, Jawa Barat.

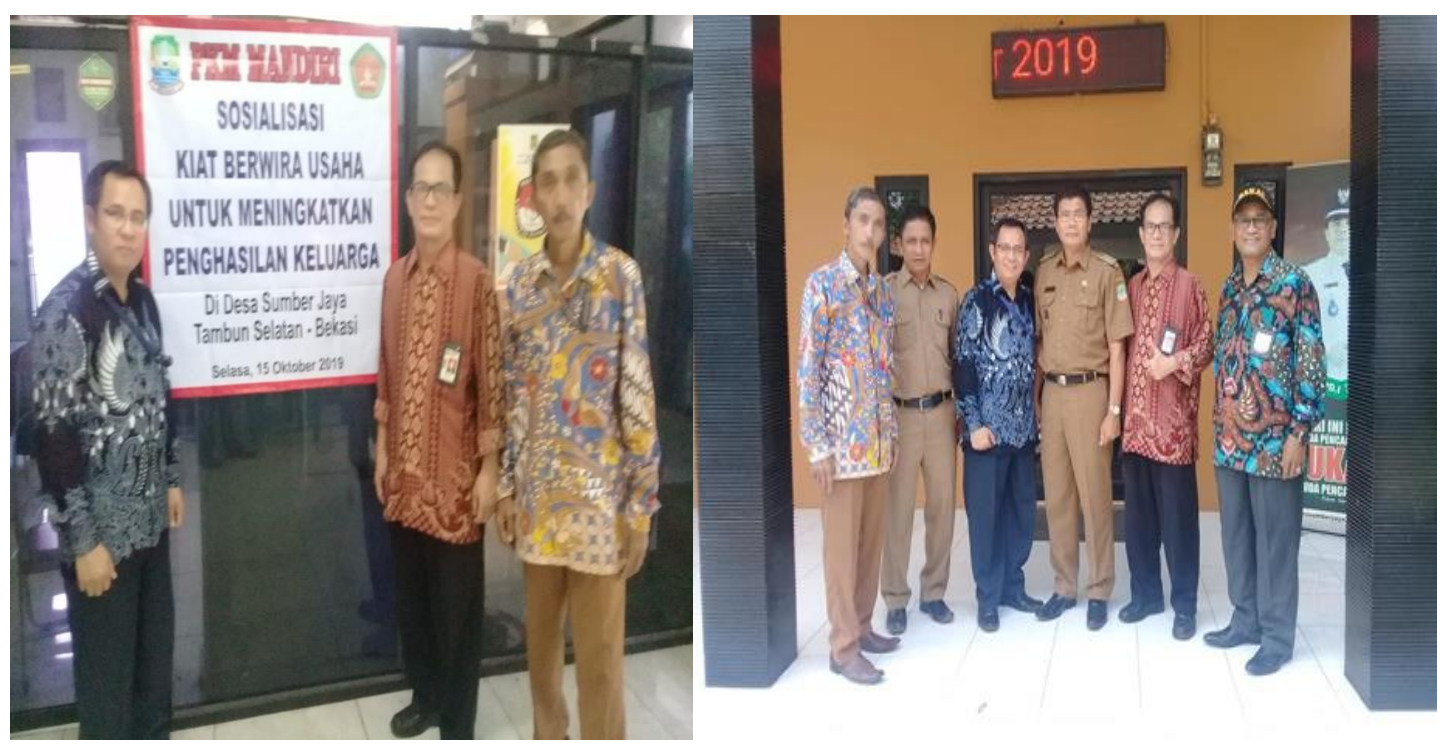

Sumber: Hasil Pelaksanaan (2021)

Gambar 3. Foto Narasumber dan Kepala Desa Sumber Jaya

\section{Kesimpulan}

Kesimpulan dari Pengabdian Kepada Masyarakat pada masyarakat Desa Sumber Jaya , Kecamatan Tambun Selatan, Kabupaten Bekasi - Jawa Barat. Pada dasarnya berjalan cukup lancar sebagaimana mestinya, dan kami merasa bahagia dengan pengalaman yang sangat berharga, dapat memberikan bekal ilmu dan pengetahuan yang kami miliki dan berbagi ilmu kepada masyarakat mitra, memperoleh nilai tambah terutama tentang Kiat Berwirausaha yang sangat membantu para Ketua RT/ RW dan Aparat Desa, dalam memimpin warganya yang memiliki berbagai macam karakter, berbagai macam tingkat pendidikan, dengan mengikuti Sosialisasi Kiat Berwirausaha dapat menjawab tantangan yang ada dimasyarakat, apalagi bagi lbu Pedagang di Rumah, UKM di bidang Kuliner dapat mengetahui bagaimana mencatat 
penerimaan dan pengeluaran yang langsung di praktekan dalam penyusunan perhitungan hasil usahanya dengan benar. Rekomendasi yang dibutuhkan dalam kegiatan Pengabdian Kepada Masyarakat yaitu kami menyadari dengan sedalam-dalamnya bahwa, kami selaku Tim Abdimas, siap menerima Kritik dan Saran, mengingat kami masih banyak kekurangan dan pengalaman dalam kegiatan kepada masyarakat, dan suatu pembelajaran buat kami. Semoga dimasa-masa yang akan datang kami Tim Abdimas, akan meningkatkan lagi kegiatan Abdimas, dan penelitian, dan menjunjung tinggi Tri Darma Perguruan Tinggi. Terakhir Kepala Desa Sumber Jaya, Bapak H. Matam, SPDI, menyampaikan ucapan terimakasih dan penghargaan kepada Dosen Fakultas Ekonomi Universitas Bhayangkara Jakarta Raya, selaku Nara Sumber kegiatan Pengabdian kepada Masyarakat semoga hubungan yang baik ini dapat ditingkatkan lagi, dimasa-masa yang akan datang demi kemajuan Nusa dan Bangsa Indonesia.

\section{Ucapan Terima Kasih (Opsional)}

Secara khusus rasa terimakasih tersebut kami sampaikan kepada a) Irjen.Pol. (Purn) Dr. Drs.H. Bambang Karsono, S.H., M.M. selaku Rektor Universitas Bhayangkara Jakarta Raya yang telah memberikan arahan dan semangat bagi para Dosen untuk terus melakukan Penelitian dan Pengabdian Kepada Masyarakat demi kemajuan di Universitas Bhayangkara Jakarta Raya; b) Dr. Istianingsih, selaku Dekan Fakultas Ekonomi Universitas Bhayangkara Jakarta Raya yang telah menyetujui untuk melakukan Pengabdian Kepada Masyarakat; c) Ir. Djuni Thamrin, Ph.D, selaku Kepala Lembaga Penelitian, Pengabdian Masyarakat dan Publikasi yang telah banyak memberikan arahan serta masukan dalam penyerpurnaan Laporan Hasil Pengabdian Kepada Masyarakat; d) Prasojo, S.Sos., M.Sos. selaku Kepala Bidang Pengabdian Kepada Masyarakat yang telah memberikan arahan serta masukan dalam penyempurnaan Laporan Pengabdian Kepada Masyarakat; e) H. Matam, SPdi, selaku Kepala Desa Sumber Jaya dan jajarannya yang telah memberikan kesempatan dan bantuan kepada tim dalam melaksanakan kegiatan Pengabdian Kepada Masyarakat ini; f) Rekan-rekan Dosen yang telah memberikan masukan dan bantuan dalam melakukan Pengabdian Kepada Masyarakat sehingga bisa terlaksana dengan baik.

\section{Daftar Pustaka}

Aditya, M. (2015). Data Produktivitas Karyawan PT Primatexco Indonesia Batang (Unit Weaving/ Pertenuan) Tahun 2011 s/d 2013.

Bramantyo. (2017, November). Potensial berkembang, ada BUMDES yang omsetnya Rp 12 Miliyar/ Tahun.

Fandyansari, M. W. (2019). Pengembangan Buku Ajar Manajemen UKM Berbasis Ekonomi Kerakyatan Bagi Mahasiswa Pendidikan Ekonomi. Economic and Education Journal. https://doi.org/https://doi.org/10.33503/ecoducation.v1i1.378

Handoko, H. (1994). Manajemen Personalia dan Sumber Daya Manusia (3rd ed.). Yogyakarta: BPFE. 
Hejirachman, \& Husna, S. (2003). Manajemen Personalia. Yogyakarta: BPFE.

Kementerian Perdagangan. (2013). Analisis Peran Lembaga Pembiayaan dalam Pengembangan UMKM.

Moelyono, M. (2010). Menggerakan Ekonomi Kreatif Antara Tuntutan dan Kebutuhan. Jakarta: PT Raja Grafindo Persada.

Narpati, B. (2018). Sosialisasi dan Simulasi Menabung Rumah Yatim Kota Bekasi. Jurnal Pengabdian Kepada Masyarakat UBJ, 1(2), 77-86. https://doi.org/https://doi.org/10.31599/jabdimas.v1i2.295

Sari, E. S. P. P. (2018). Jurnal UMKM Dewantara. Jurnal UMKM Dewantara, 1(1).

Sinungan, M. (2000). Produktivitas Apa dan Bagaimana (2nd ed.). Jakarta: Bumi Aksara.

Suryana. (2013). Ekonomi Kreatif Ekonomi Baru. Jakarta: Salemba Empat. 